\title{
Biological Strategies to Enhance Healing of the Avascular Area of the Meniscus
}

\author{
Umile Giuseppe Longo, ${ }^{1,2}$ Stefano Campi, ${ }^{1,2}$ Giovanni Romeo, ${ }^{1,2}$ Filippo Spiezia,, 2 \\ Nicola Maffulli, ${ }^{3}$ and Vincenzo Denaro ${ }^{1,2}$ \\ ${ }^{1}$ Department of Orthopaedic and Trauma Surgery, Campus Bio-Medico University, Via Alvaro del Portillo, 200, 00128 Rome, Italy \\ ${ }^{2}$ Centro Integrato di Ricerca (CIR), Università Campus Bio-Medico di Roma, Via Alvaro del Portillo, 21, 00128 Roma, Italy \\ ${ }^{3}$ Centre for Sports and Exercise Medicine, Barts and The London School of Medicine and Dentistry, Mile End Hospital, \\ 275 Bancroft Road, London E1 4DG, UK \\ Correspondence should be addressed to Umile Giuseppe Longo, g.longo@unicampus.it
}

Received 15 September 2011; Accepted 1 November 2011

Academic Editor: Wasim S. Khan

Copyright () 2012 Umile Giuseppe Longo et al. This is an open access article distributed under the Creative Commons Attribution License, which permits unrestricted use, distribution, and reproduction in any medium, provided the original work is properly cited.

\begin{abstract}
Meniscal injuries in the vascularized peripheral part of the meniscus have a better healing potential than tears in the central avascular zone because meniscal healing principally depends on its vascular supply. Several biological strategies have been proposed to enhance healing of the avascular area of the meniscus: abrasion therapy, fibrin clot, organ culture, cell therapy, and applications of growth factors. However, data are too heterogeneous to achieve definitive conclusions on the use of these techniques for routine management of meniscal lesions. Although most preclinical and clinical studies are very promising, they are still at an experimental stage. More prospective randomised controlled trials are needed to compare the different techniques for clinical results, applicability, and cost-effectiveness.
\end{abstract}

\section{Introduction}

The menisci of the knee are two semilunar fibrocartilaginous structures sitting between the joint surfaces of femoral condyles and the tibial plateau. Meniscal injuries are a common and important source of knee dysfunction. Repair should be considered depending on the type and location of the meniscal tear [1-3], as meniscal healing principally depends on the vascular supply of the zone that has been injured [4]. A rich network of arborizing vessels within the peripheral capsular and synovial attachments supplies vascularization to the menisci. This perimeniscal network provides radial branches to the meniscus. The outer third of the meniscus is vascularised, showing a good healing capacity. Given its abundant vascularization, this zone is also called "red-red zone." The remaining two-thirds of the meniscus, respectively called "red-white zone" and "whitewhite zone," have a scanty vascular supply and present a limited ability to heal spontaneously [4-7].

A meniscal lesion followed by disruption of the structure in the avascular zone impairs load distribution and initiates erosion of the adjacent articular surfaces, causing osteoarthritis (OA) [8-11]. The most common treatment for lesions of the avascular part of the meniscus is arthroscopic partial meniscectomy, which reduces symptoms but similarly predisposes patients to OA [12]. Studies have demonstrated that healing of the knee is inversely related to the amount of resected meniscal tissue $[10,11,13,14]$. Meniscal repair techniques in the avascular zone are in continuous evolution.

This paper covers current knowledge on biological strategies for the stimulation of meniscal healing after repair.

\section{Abrasion Therapy}

Rasping of the damaged meniscus in the vascularized parameniscal synovium promotes an injury response and is one of the most simple and effective strategies to favour healing [3]. A small incision is performed to produce a vascular channel that redirects the blood flow from the vascular zone into the avascular one. Several studies showed a significant difference in healing between menisci treated 
with abrasion therapy and control groups $[15,16]$. The most common techniques of abrasion therapy are rasping or trephination, in which radially oriented channels are performed to encourage vascular and cellular migration from the peripheral vascular portion to the tear site [17-19]. Rasping increases the production of interleukin-I-alpha (IL1-alpha), transforming-growth-factor-beta 1 (TGF-beta1), platelet-derived growth factor (PDGF), and proliferating cell nuclear antigen (PCNA). This protein network improves vascular induction and meniscal healing [20]. Nevertheless, trephination and rasping procedures may damage the normal meniscal structure by an additional full thicknesstransverse tear, resulting in poor meniscal function.

\section{Fibrin Clot}

Fibrin is a fibrous protein produced in response to bleeding that plays an important role in blood clotting. Fibrin clots may be used topically or by injection as an haemostatic agent, binding to several adhesive proteins of different cells. The fibrin clot technique acts as a chemotactic and mitogenic stimulus for reparative cells because of the presence of several growth factors [21-24]. The fibrin clot attaches to the exposed collagen caused by the tear and induces proliferation of fibrous connective tissue. This stimulates the development of fibrocartilaginous tissue. The fibrin clot technique can be used in combination with abrasion therapy or with meniscal sutures. Two studies in animal models showed that organized fibrous connective tissue developed into cartilaginous tissue after a period of 12-24 weeks [25, 26]. A potential disadvantage of the fibrin clot technique is the difficulty of keeping fibrin clots on the tear without immobilizing the operated leg [27].

\section{Organ Culture}

Organ culture is a useful model to assess the intrinsic healing potential of the meniscus excluding the influence of microvasculature and the synovium [28-30]. The effects of cultured meniscal explants in a rabbit model have been reported [30]. After gross evaluation, each meniscal explant underwent histological evaluation to study the relationship between the graft and recipient tissue. Application of this technique has demonstrated that meniscal tissue presents an intrinsic healing ability, which is greater in the peripheral zone of the meniscus than in the inner zone [30]. Regional differences in healing potential and extrinsic factors, such as blood supply, could explain good meniscal healing in the peripheral zone.

\section{Cell Therapy}

Human menisci are populated by different cell types, responding differently to various stimuli released from the matrix [31, 32]. Different cells have already been used in studies on meniscal healing: mesenchymal stem cells (MSCs) deriving from synovial or bone marrow, chondrocytes, and fibrochondrocytes. MSCs are pluripotent cells able to differentiate into specific therapeutic cell types (developmental plasticity) [33-35]. The effects of bioactive molecules, which are secreted by MSCs, determine a regenerative microenvironment that promotes healing of meniscal lesions $[36,37]$. The combination of suturing and MSC treatment, combined or not with fibrin glue, seems to be the most effective treatment [38].

Zellner et al. [37] reported the efficacy of mesenchymal stem cells in the repair of meniscal defects in the avascular zone. Nonprecultured mesenchymal stem cells in hyaluronan-collagen composite matrices stimulated the development of completely integrated meniscus-like repair tissue in defects produced in the avascular zone of rabbit menisci [37].

Further studies confirm the production of abundant extracellular matrix around the cells, restoring a meniscallike tissue in the avascular zone [37,39-42]. These results are supported by early studies which demonstrated the efficacy of the association between growth factors and mesenchymal stem cells within scaffold implants to increase proteoglycans and/or collagen synthesis [37, 43]. Articular autologous and allogenic chondrocytes have also been used to induce repair in the avascular part of the meniscus [44, 45]. Peretti et al. described a porcine chondrocyte model where implantation of such cells was performed in the avascular part of the meniscus using an allogenic scaffold seeded with autologous chondrocytes. These chondrocytes were effective in promoting healing meniscal tears [44]. Fibrochondrocytes showed potential for initiating a reparative response in meniscal defects through the production of new extracellular matrix (ECM) [46, 47]. When seeded into a porous collagen scaffold, fibrochondrocytes harvested from the inner avascular part of the meniscus produce more glycosaminoglycans (GAGs) than fibrochondrocytes from a peripheral fibrous location $[48,49]$. Although these findings are encouraging, the application of autologous fibrochondrocytes in meniscal tissue engineering is limited by the difficulty in harvesting a sufficient number of cells.

\section{Growth Factors}

Growth factors act as signalling molecules on target cells to stimulate the regeneration of damaged tissue [6]. Furthermore, they can induce the synthesis and inhibit degradation of ECM by a mechanism of downregulation of proteases [50]. Several studies in vitro and in vivo evaluated the effects of treatment with specific growth factors. Two categories of growth factors in consideration of their biochemical attributes are generally considered: anabolic and catabolic growth factors.

\subsection{Anabolic Growth Factors}

6.1.1. Fibroblast Growth Factor (FGF). basic FGF was used to stimulate type II collagen and aggrecan mRNA production in cellular and tissue development $[51,52]$. In an ovine experimental model, meniscal fibrochondrocytes responded to bFGF by proliferating and producing new extracellular 
matrix [46]. Another FGF type, FGF-2, stimulates proliferation of the joint chondrocytes, mesenchymal stem cells, osteoblasts, and adipocytes. Furthermore, it maintains the ability of any cell types to differentiate [53, 54]. Moreover, a hyperexpression of FGF-2 and alpha-smooth muscle actin (alpha-SMA) through recombinant adeno-associated virus (rAAV) enhanced cell proliferation and increased survival rate compared with control groups. However, FGF did not significantly increase the synthesis of major extracellular matrix components or DNA contents [55].

6.1.2. Transforming-Growth-Factor-Beta-I (TGF-Beta-I). TGF-beta-I seems to have several regulatory activities, stimulating collagen and proteoglycan production to increase the attachment of the cells in repaired meniscal tissue. Nevertheless, it has no effect on cell proliferation $[6,56-59]$.

6.1.3. Bone Morphogenetic Proteins (BMPs). BMPs are a group of growth factors belonging to the TGF- $\beta$ superfamily playing an important role during embryogenesis and tissue repair in relation to their osteoinductive properties [60, 61]. BMP-2 acts as a stimulus in the differentiation of mesenchymal cells. It also presents a migratory effect in endothelial cells or smooth muscle cells, but rarely in chondrocytes [62]. BMP-7 regulates matrix homeostasis and inhibits the processes of degradation. BMP-7 acts with different chondrogenic agents and is more effective than BMP-2 in chondrogenic differentiation of MSCs in promoting meniscal healing [63].

6.1.4. Insulin-Like-Growth-Factor-I (IGF-I). This is considered the main anabolic growth factor for articular cartilage $[64,65]$. Unlike TGF-beta-I, IGF-I increases cell proliferation significantly but has no effect on the attachment [51]. Therefore, a mixture of growth factors in association with IGF-I could induce an extensive cellular response to mediate avascular meniscal healing [56].

6.1.5. Vascular Endothelial Growth Factor (VEGF). The induction of angiogenesis is important to stimulate healing of meniscal tears. Vascular endothelial growth factor (VEGF) may promote better healing, stimulating angiogenesis to improve the healing capacities of meniscus tissue. In adults, VEGF expression is downregulated by endostatin, mostly in the avascular zone [66]. However, the local application of VEGF did not show an improvement of meniscal healing [67].

6.1.6. Platelet-Derived Growth Factor-AB (PDGF-AB). PDGF-AB plays an important role in the angiogenesis and cell development $[68,69]$. The application of PDGF-AB in the peripheral part of the menisci showed a better healing response than the application in the central part [70]. However, this anabolic growth factor increased both cell proliferation and ECM formation in all zones of the meniscus, including the avascular zone [71].

\subsection{Catabolic Growth Factors}

6.2.1. Endostatin. Endostatin is an antiangiogenic factor expressed by fibrochondrocytes in the avascular zone of menisci. Endostatin concentrations were higher when fibrochondrocytes were in coculture with MSCs, suggesting that meniscal cell growth is inhibited by the proliferation of MSCs [7].

6.2.2. Interleukin-I (IL-I). This is a proinflammatory cytokine that stimulates the development of a local inflammatory reaction. Meniscal explants treated with IL-I have failed to show any signs of regeneration [72]. These findings suggest that relevant expression of IL-I in association with higher levels of tumor-necrosis-factor-alpha (TNF-alpha) inhibit meniscal repair [73].

\section{Platelet Rich Plasma}

Platelet-rich plasma (PRP) is an autologous substance rich in platelets that releases growth factors from both alpha and dense granules. These growth factors have been associated with the initiation of a healing cascade leading to cellular chemotaxis, angiogenesis, collagen matrix synthesis, and cell proliferation [74]. Ishida et al. reported the effects of PRP on meniscal tissue regeneration, both in vitro and in vivo, in a rabbit model. In the in vitro study, monolayer meniscal cell cultures were prepared and proliferative behaviour, extracellular matrix (ECM) synthesis, and fibrocartilagerelated messenger ribonucleic acid (mRNA) expressions were assessed in the presence of PRP. PRP stimulated DNA synthesis, ECM synthesis, and mRNA expression of biglycan and decorin. In the in vivo study, full-thickness defects were produced in the avascular region of rabbit meniscus. Gelatin hydrogel $(\mathrm{GH})$ was used to deliver PRP into the defects. At histology 12 weeks after surgery, significantly better meniscal repair was evident in animals that received PRP with GH than in the control groups [75].

In contrast, Zellner et al. evaluated several cell and biomaterial-based treatment options for repair of defects in the avascular zone of rabbit menisci by producing circular meniscal punch defects in the avascular zone of rabbit menisci. The defects were left empty or filled with hyaluronan-collagen composite matrices without cells loaded with platelet-rich plasma, autologous bone marrow, or autologous mesenchymal stem cells. Neither bone marrow nor platelet-rich plasma loaded in matrices induced improvement in meniscal healing [37].

\section{Discussion}

In the last few decades, many studies on meniscal healing have focused on methods to enhance the healing capacities of the meniscus after repair. Abrasion of the torn meniscus and synovial tissue or the establishment of vascular channels to redirect blood flow into the avascular zone seems to be the preferred treatment $[3,15,16]$. However, the healing potential depends on the type and location of the tear and 
its distance from the peripheral vascularised zone. The use of a fibrin clot can also be an effective technique to support a reparative response in the avascular zone of the meniscus [21, $22,24]$. Findings demonstrated that the rasping technique is more effective than fibrin clot application to improve meniscal healing [76]. Kobayashi et al. reported healing rates in the peripheral zone of the menisci in an on-organ culture model. Regional differences in healing potential and extrinsic factors, such as a blood supply, could explain the good meniscal healing potential in the peripheral zone [30].

Cell-based therapy for meniscal tears has significantly contributed to an increasing number of patients treated with repair techniques rather than meniscectomy. Different cell types have already been used in studies on meniscus healing: MSCs, articular chondrocytes and autologous fibrochondrocytes [37, 44, 48, 49]. Progenitor cells such as mesenchymal stem cells present the advantage of being easily expandable without losing their differentiation potential into a variety of mesenchymal tissues including bone, tendon, cartilage, muscle, ligament, fat, and marrow stroma [31, 33, 35]. The application of MSCs and their stimulation with growth factors in combination with a mechanically loadable scaffold have been proposed as the focus of future studies $[77,78]$.

Several studies reported the efficacy of mesenchymal stem cells in the repair of meniscal defects in the avascular zone, with production of abundant extracellular matrix around the cells and restoration of a meniscal-like tissue [37, 39-42]. Early studies demonstrated the efficacy of the association between growth factors and mesenchymal stem cells within scaffold implants to increase proteoglycan and/or collagen synthesis. Therefore, the healing response of mesenchymal stem cells seems to produce additional repair qualities besides the delivery of growth factors [37, 43].

Many studies have shown the importance of growth factors in the treatment of meniscal tears of the avascular portion, but there is a very complex interplay among a variety of factors that influences healing processes. Growth factors that promote cell differentiation and chondrocytic proliferation include both anabolic growth factors (TGF-betaI, BMPs, IGF-I, FGF, VEGF, and PDGF-AB) and catabolic growth factors (endostatin, IL-1, and TNF-alpha). Anabolic growth factors could be of additional value in improving the healing of meniscal lesions $[6,46,51-57]$. However, the application of growth factors remains very limited in clinical settings $[6,51]$. Future research should focus on the use of tissue-engineered constructs in association with different growth factors. A preparation rich in growth factors could produce better results than the use of isolated growth factors. Only a few studies to date have evaluated the effectiveness of a preparation of platelet-rich plasma (PRP), but there is some evidence that PRP can improve healing of the menisci $[70,71]$. The release of growth factors from platelets has been associated with the initiation of a healing cascade leading to cellular chemotaxis, angiogenesis, collagen matrix synthesis, and cell proliferation $[74,75]$. In contrast, a study in an animal model reported that application of PRP did not produce improvements in meniscal healing [37].

\section{Conclusion}

Patients with meniscal tears report pain and functional limitation of the knee joint. Partial meniscectomy is the most common treatment option, but it represents a predisposing factor for osteoarthritis [12]. To date only limited scientifically proven management modalities are available. A better understanding of meniscal healing mechanisms will allow specific treatment strategies to be developed. Although most preclinical and clinical studies are very promising, they are still at an experimental stage. Further prospective trials are necessary to compare the different techniques for efficacy, applicability, and cost-effectiveness in the management of lesions of the avascular region of the meniscus.

\section{References}

[1] E. Rath and J. C. Richmond, "The menisci: basic science and advances in treatment," British Journal of Sports Medicine, vol. 34 , no. 4, pp. 252-257, 2000.

[2] K. Messner and J. Gao, "The menisci of the knee joint. Anatomical and functional characteristics, and a rationale for clinical treatment," Journal of Anatomy, vol. 193, no. 2, pp. 161-178, 1998.

[3] S. P. Arnoczky and R. F. Warren, "The microvasculature of the meniscus and its response to injury. An experimental study in the dog," American Journal of Sports Medicine, vol. 11, no. 3, pp. 131-141, 1983.

[4] S. P. Arnoczky and R. F. Warren, "microvasculature of the human meniscus," American Journal of Sports Medicine, vol. 10, no. 2, pp. 90-95, 1982.

[5] F. N. Ghadially, J. M. A. Lalonde, and J. H. Wedge, "Ultrastructure of normal and torn menisci of the human knee joint," Journal of Anatomy, vol. 136, no. 4, pp. 773-791, 1983.

[6] F. Forriol, "Growth factors in cartilage and meniscus repair," Injury, vol. 40, supplement 3, pp. S12-S16, 2009.

[7] M. Hoberg, E. L. Schmidt, M. Tuerk, V. Stark, W. K. Aicher, and M. Rudert, "Induction of endostatin expression in meniscal fibrochondrocytes by co-culture with endothelial cells," Archives of Orthopaedic and Trauma Surgery, vol. 129, no. 8, pp. 1137-1143, 2009.

[8] W. R. Krause, M. H. Pope, R. J. Johnson, and D. G. Wilder, "Mechanical changes in the knee after meniscectomy," Journal of Bone and Joint Surgery —Series A, vol. 58, no. 5, pp. 599-604, 1976.

[9] I. M. Levy, P. A. Torzilli, J. D. Gould, and R. F. Warren, "The effect of lateral meniscectomy on motion of the knee," Journal of Bone and Joint Surgery —Series A, vol. 71, no. 3, pp. 401-406, 1989.

[10] H. Roos, M. Laurén, T. Adalberth, E. M. Roos, K. Jonsson, and L. S. Lohmander, "Knee osteoarthritis after meniscectomy: prevalence of radiographic changes after twenty-one years, compared with matched controls," Arthritis and Rheumatism, vol. 41, no. 4, pp. 687-693, 1998.

[11] H. Roos, T. Adalberth, L. Dahlberg, and L. S. Lohmander, "Osteoarthritis of the knee after injury to the anterior cruciate ligament or meniscus: the influence of time and age," Osteoarthritis and Cartilage, vol. 3, no. 4, pp. 261-267, 1995.

[12] F. Forriol, U. G. Longo, D. Hernández-Vaquero et al., "The effects of previous meniscus and anterior cruciate ligament injuries in patients with total knee arthroplasty," Ortopedia Traumatologia Rehabilitacja, vol. 12, no. 1, pp. 50-57, 2010. 
[13] I. D. McDermott and A. A. Amis, "The consequences of meniscectomy," Journal of Bone and Joint Surgery-Series B, vol. 88, no. 12, pp. 1549-1556, 2006.

[14] M. Englund, A. Guermazi, and L. S. Lohmander, "The meniscus in knee osteoarthritis," Rheumatic Disease Clinics of North America, vol. 35, no. 3, pp. 579-590, 2009.

[15] D. H. Gershuni, M. J. Skyhar, L. A. Danzig, J. Camp, A. R. Hargens, and W. H. Akeson, "Experimental models to promote healing of tears in the avascular segment of canine knee menisci," Journal of Bone and Joint Surgery-Series A, vol. 71, no. 9, pp. 1363-1370, 1989.

[16] K. Okuda, M. Ochi, N. Shu, and Y. Uchio, "Meniscal rasping for repair of meniscal tear in the avascular zone," Arthroscopy, vol. 15, no. 3, pp. 281-286, 1999.

[17] Z. Zhang, K. Tu, Y. Xu, W. Zhang, Z. Liu, and S. Ou, "Treatment of longitudinal injuries in avascular area of meniscus in dogs by trephination," Arthroscopy, vol. 4, no. 3, pp. 151-159, 1988.

[18] Z. Zhang, J. A. Arnold, T. Willlams, B. McCann, and W. D. Cannon, "Repairs by trephination and suturing of longitudinal injuries in the avascular area of the meniscus in goats," American Journal of Sports Medicine, vol. 23, no. 1, pp. 35-41, 1995.

[19] J. L. Cook and D. B. Fox, "A novel bioabsorbable conduit augments healing of avascular meniscal tears in a dog model," American Journal of Sports Medicine, vol. 35, no. 11, pp. 18771887, 2007.

[20] M. Ochi, Y. Uchio, K. Okuda, N. Shu, H. Yamaguchi, and Y. Sakai, "Expression of cytokines after meniscal rasping to promote meniscal healing," Arthroscopy, vol. 17, no. 7, pp. 724-731, 2001.

[21] S. P. Arnoczky, R. F. Warren, and J. M. Spivak, "Meniscal repair using an exogenous fibrin clot. An experimental study in dogs," Journal of Bone and Joint Surgery-Series A, vol. 70, no. 8, pp. 1209-1217, 1988 .

[22] C. E. Henning, M. A. Lynch, K. M. Yearout, S. W. Vequist, R. J. Stallbaumer, and K. A. Decker, "Arthroscopic meniscal repair using an exogenous fibrin clot," Clinical Orthopaedics and Related Research, no. 252, pp. 64-72, 1990.

[23] M. Ishimura, S. Tamai, and Y. Fujisawa, "Arthroscopic meniscal repair with fibrin glue," Arthroscopy, vol. 7, no. 2, pp. 177181, 1991.

[24] M. F. van Trommel, P. T. Simonian, H. G. Potter, and T. L. Wickiewicz, "Arthroscopic meniscal repair with fibrin clot of complete radial tears of the lateral meniscus in the avascular zone," Arthroscopy, vol. 14, no. 4, pp. 360-365, 1998.

[25] J. Hashimoto, M. Kurosaka, S. Yoshiya, and K. Hirohata, "Meniscal repair using fibrin sealant and endothelial cell growth factor. An experimental study in dogs," American Journal of Sports Medicine, vol. 20, no. 5, pp. 537-541, 1992.

[26] J. Port, D. W. Jackson, T. Q. Lee, and T. M. Simon, "Meniscal repair supplemented with exogenous fibrin clot and autogenous cultured marrow cells in the goat model," American Journal of Sports Medicine, vol. 24, no. 4, pp. 547-555, 1996.

[27] R. C. Bray, J. A. Smith, M. K. Eng, C. A. Leonard, C. A. Sutherland, and P. T. Salo, "Vascular response of the meniscus to injury: effects of immobilization," Journal of Orthopaedic Research, vol. 19, no. 3, pp. 384-390, 2001.

[28] M. Ochi, Y. Mochizuki, M. Deie, and Y. Ikuta, "Augmented meniscal healing with free synovial autografts: an organ culture model," Archives of Orthopaedic and Trauma Surgery, vol. 115, no. 3-4, pp. 123-126, 1996.

[29] I. Mitani, S. Sumita, N. Takahashi, H. Ochiai, and M. Ishii, "123I-MIBG myocardial imaging in hypertensive patients: abnormality progresses with left ventricular hypertrophy," Annals of Nuclear Medicine, vol. 10, no. 3, pp. 315-321, 1996.

[30] K. Kobayashi, E. Fujimoto, M. Deie, Y. Sumen, Y. Ikuta, and M. Ochi, "Regional differences in the healing potential of the meniscus - an organ culture model to eliminate the influence of microvasculature and the synovium," Knee, vol. 11, no. 4, pp. 271-278, 2004.

[31] P. C. M. Verdonk, R. G. Forsyth, J. Wang et al., "Characterisation of human knee meniscus cell phenotype," Osteoarthritis and Cartilage, vol. 13, no. 7, pp. 548-560, 2005.

[32] C. Stärke, S. Kopf, W. Petersen, and R. Becker, "Meniscal repair," Arthroscopy, vol. 25, no. 9, pp. 1033-1044, 2009.

[33] M. Ohishi and E. Schipani, "Bone marrow mesenchymal stem cells," Journal of Cellular Biochemistry, vol. 109, no. 2, pp. 277282, 2010.

[34] U. Nöth, A. M. Osyczka, R. Tuli, N. J. Hickok, K. G. Danielson, and R. S. Tuan, "Multilineage mesenchymal differentiation potential of human trabecular bone-derived cells," Journal of Orthopaedic Research, vol. 20, no. 5, pp. 1060-1069, 2002.

[35] R. O. C. Oreffo, C. Cooper, C. Mason, and M. Clements, "Mesenchymal stem cells lineage, plasticity, and skeletal therapeutic potential," Stem Cell Reviews, vol. 1, no. 2, pp. 169178, 2005.

[36] J. L. Cook, "The current status of treatment for large meniscal defects," Clinical Orthopaedics and Related Research, no. 435, pp. 88-95, 2005.

[37] J. Zellner, M. Mueller, A. Berner et al., "Role of mesenchymal stem cells in tissue engineering of meniscus," Journal of Biomedical Materials Research-Part A, vol. 94, no. 4, pp. 1150-1161, 2010.

[38] M. Abdel-Hamid, M. R. Hussein, A. F. Ahmad, and E. M. Elgezawi, "Enhancement of the repair of meniscal wounds in the red-white zone (middle third) by the injection of bone marrow cells in canine animal model," International Journal of Experimental Pathology, vol. 86, no. 2, pp. 117-123, 2005.

[39] Y. Izuta, M. Ochi, N. Adachi, M. Deie, T. Yamasaki, and R. Shinomiya, "Meniscal repair using bone marrow-derived mesenchymal stem cells: experimental study using green fluorescent protein transgenic rats," Knee, vol. 12, no. 3, pp. 217-223, 2005.

[40] K. R. Stone, W. G. Rodkey, R. Webber, L. McKinney, and J. R. Steadman, "Meniscal regeneration with copolymeric collagen scaffolds. In vitro and in vivo studies evaluated clinically, histologically, and biochemically," American Journal of Sports Medicine, vol. 20, no. 2, pp. 104-111, 1992.

[41] A. F. Steinert, G. D. Palmer, R. Capito et al., "Genetically enhanced engineering of meniscus tissue using ex vivo delivery of transforming growth factor- $\beta 1$ complementary deoxyribonucleic acid," Tissue Engineering, vol. 13, no. 9, pp. 2227-2237, 2007.

[42] A. Q. Dutton, P. F. Choong, J. C. H. Goh, E. H. Lee, and J. H. P. Hui, "Enhancement of meniscal repair in the avascular zone using mesenchymal stem cells in a porcine model," Journal of Bone and Joint Surgery —Series B, vol. 92, no. 1, pp. 169-175, 2010.

[43] M. B. Pabbruwe, W. Kafienah, J. F. Tarlton, S. Mistry, D. J. Fox, and A. P. Hollander, "Repair of meniscal cartilage white zone tears using a stem cell/collagen-scaffold implant," Biomaterials, vol. 31, no. 9, pp. 2583-2591, 2010.

[44] G. M. Peretti, T. J. Gill, J. W. Xu, M. A. Randolph, K. R. Morse, and D. J. Zaleske, "Cell-based therapy for meniscal repair: a large animal study," American Journal of Sports Medicine, vol. 32, no. 1, pp. 146-158, 2004. 
[45] C. Weinand, G. M. Peretti, S. B. Adams, M. A. Randolph, E. Savvidis, and T. J. Gill, "Healing potential of transplanted allogeneic chondrocytes of three different sources in lesions of the avascular zone of the meniscus: a pilot study," Archives of Orthopaedic and Trauma Surgery, vol. 126, no. 9, pp. 599-605, 2006.

[46] N. S. Tumia and A. J. Johnstone, "Promoting the proliferative and synthetic activity of knee meniscal fibrochondrocytes using basic fibroblast growth factor in vitro," American Journal of Sports Medicine, vol. 32, no. 4, pp. 915-920, 2004.

[47] J. L. Vander Schilden, J. L. York, and R. J. Webber, "Agedependent fibrin clot invasion by human meniscal fibrochondrocytes. A preliminary report," Orthopaedic Review, vol. 20, no. 12, pp. 1089-1097, 1991.

[48] K. Nakata, K. Shino, M. Hamada et al., "Human meniscus cell: characterization of the primary culture and use for tissue engineering," Clinical Orthopaedics and Related Research, no. 391, pp. S208-S218, 2001.

[49] T. Tanaka, K. Fujii, and Y. Kumagae, "Comparison of biochemical characteristics of cultured fibrochondrocytes isolated from the inner and outer regions of human meniscus," Knee Surgery, Sports Traumatology, Arthroscopy, vol. 7, no. 3, pp. 75-80, 1999.

[50] S. P. Arnoczky, "Building a meniscus. Biologic considerations," Clinical Orthopaedics and Related Research, pp. S244-S253, 1999.

[51] D. B. Fox, J. J. Warnock, A. M. Stoker, J. K. Luther, and M. Cockrell, "Effects of growth factors on equine synovial fibroblasts seeded on synthetic scaffolds for avascular meniscal tissue engineering," Research in Veterinary Science, vol. 88, no. 2, pp. 326-332, 2010.

[52] T. Vincent, M. Hermansson, M. Bolton, R. Wait, and J. Saklatvala, "Basic FGF mediates an immediate response of articular cartilage to mechanical injury," Proceedings of the National Academy of Sciences of the United States of America, vol. 99, no. 12, pp. 8259-8264, 2002.

[53] A. Narita, M. Takahara, T. Ogino, S. Fukushima, Y. Kimura, and Y. Tabata, "Effect of gelatin hydrogel incorporating fibroblast growth factor 2 on human meniscal cells in an organ culture model," Knee, vol. 16, no. 4, pp. 285-289, 2009.

[54] I. Martin, A. Muraglia, G. Campanile, R. Cancedda, and R. Quarto, "Fibroblast growth factor-2 supports ex vivo expansion and maintenance of osteogenic precursors from human bone marrow," Endocrinology, vol. 138, no. 10, pp. 4456-4462, 1997.

[55] M. Cucchiarini, S. Schetting, E. F. Terwilliger, D. Kohn, and H. Madry, "rAAV-mediated overexpression of FGF-2 promotes cell proliferation, survival, and $\alpha$-SMA expression in human meniscal lesions," Gene Therapy, vol. 16, no. 11, pp. 13631372, 2009.

[56] I. Izal, P. Ripalda, C. A. Acosta, and F. Forriol, "In vitro healing of avascular meniscal injuries with fresh and frozen plugs treated with TGF-betal and IGF-1 in sheep," International Journal of Clinical and Experimental Pathology, vol. 1, pp. 426434, 2008.

[57] S. Collier and P. Ghosh, "Effects of transforming growth factor beta on proteoglycan synthesis by cell and explant cultures derived from the knee joint meniscus," Osteoarthritis and Cartilage, vol. 3, no. 2, pp. 127-138, 1995.

[58] C. A. Pangborn and K. A. Athanasiou, "Effects of growth factors on meniscal fibrochondrocytes," Tissue Engineering, vol. 11, no. 7-8, pp. 1141-1148, 2005.

[59] D. J. Huey and K. A. Athanasiou, "Maturational growth of self-assembled, functional menisci as a result of TGF- $\beta 1$ and enzymatic chondroitinase-ABC stimulation," Biomaterials, vol. 32, pp. 2052-2058, 2011.

[60] E. Ozkaynak, P. N. J. Schnegelsberg, D. F. Jin et al., "Osteogenic protein-2. A new member of the transforming growth factor- $\beta$ superfamily expressed early in embryogenesis," The Journal of Biological Chemistry, vol. 267, no. 35, pp. 25220-25227, 1992.

[61] J. M. Wozney and V. Rosen, "Bone morphogenetic protein and bone morphogenetic protein gene family in bone formation and repair," Clinical Orthopaedics and Related Research, no. 346, pp. 26-37, 1998.

[62] N. Fukui, Y. Zhu, W. J. Maloney, J. Clohisy, and L. J. Sandell, "Stimulation of BMP-2 expression by pro-inflammatory cytokines IL- 1 and TNF- $\alpha$ in normal and osteoarthritic chondrocytes," Journal of Bone and Joint Surgery-Series A, vol. 85, no. 3, pp. 59-66, 2003.

[63] N. Shintani and E. B. Hunziker, "Chondrogenic differentiation of bovine synovium: bone morphogenetic proteins 2 and 7 and transforming growth factor $\beta 1$ induce the formation of different types of cartilaginous tissue," Arthritis and Rheumatism, vol. 56, no. 6, pp. 1869-1879, 2007.

[64] H. J. Im, C. Pacione, S. Chubinskaya, A. J. van Wijnen, Y. Sun, and R. F. Loeser, "Inhibitory effects of insulin-like growth factor-1 and osteogenic protein-1 on fibronectin fragmentand interleukin- $1 \beta$-stimulated matrix metalloproteinase- 13 expression in human chondrocytes," The Journal of Biological Chemistry, vol. 278, no. 28, pp. 25386-25394, 2003.

[65] P. Buma, N. N. Ramrattan, T. G. van Tienen, and R. P. H. Veth, "Tissue engineering of the meniscus," Biomaterials, vol. 25, no. 9, pp. 1523-1532, 2004.

[66] T. Pufe, W. J. Petersen, N. Miosge et al., "Endostatin/collagen XVIII - an inhibitor of angiogenesis - is expressed in cartilage and fibrocartilage," Matrix Biology, vol. 23, no. 5, pp. 267-276, 2004.

[67] W. Petersen, T. Pufe, C. Stärke et al., "Locally applied angiogenic factors-a new therapeutic tool for meniscal repair," Annals of Anatomy, vol. 187, no. 5-6, pp. 509-519, 2005.

[68] G. R. Grotendorst, G. R. Martin, and D. Pencev, "Stimulation of granulation tissue formation by platelet-derived growth factor in normal and diabetic rats," The Journal of Clinical Investigation, vol. 76, no. 6, pp. 2323-2329, 1985.

[69] K. Kirchberg, T. S. Lange, E. C. Klein et al., "Induction of $\beta 1$ integrin synthesis by recombinant platelet-derived growth factor (PDGF-AB) correlates with an enhanced migratory response of human dermal fibroblasts to various extracellular matrix proteins," Experimental Cell Research, vol. 220, no. 1, pp. 29-35, 1995.

[70] K. P. Spindler, C. E. Mayes, R. R. Miller, A. K. Imro, and J. M. Davidson, "Regional mitogenic response of the meniscus to platelet-derived growth factor (PDGF-AB)," Journal of Orthopaedic Research, vol. 13, no. 2, pp. 201-207, 1995.

[71] N. S. Tumia and A. J. Johnstone, "Platelet derived growth factor-AB enhances knee meniscal cell activity in vitro," Knee, vol. 16, no. 1, pp. 73-76, 2009.

[72] A. L. McNulty, B. T. Estes, R. E. Wilusz, J. B. Weinberg, and F. Guilak, "Dynamic loading enhances integrative meniscal repair in the presence of interleukin-1," Osteoarthritis and Cartilage, vol. 18, no. 6, pp. 830-838, 2010.

[73] A. L. McNulty, F. T. Moutos, J. B. Weinberg, and F. Guilak, "Enhanced integrative repair of the porcine meniscus in vitro by inhibition of interleukin-1 or tumor necrosis factor $\alpha$," Arthritis and Rheumatism, vol. 56, no. 9, pp. 3033-3043, 2007.

[74] D. Delos and S. A. Rodeo, "Enhancing meniscal repair through biology: platelet-rich plasma as an alternative strategy," Instructional Course Lectures, vol. 60, pp. 453-460, 2011. 
[75] K. Ishida, R. Kuroda, M. Miwa et al., “The regenerative effects of platelet-rich plasma on meniscal cells in vitro and its in vivo application with biodegradable gelatin hydrogel," Tissue Engineering, vol. 13, no. 5, pp. 1103-1112, 2007.

[76] J. R. Ritchie, M. D. Miller, R. T. Bents, and D. K. Smith, "Meniscel repair in the goat model: the use of healing adjuncts on central tears and the role of magnetic resonance arthrography in repair evaluation," American Journal of Sports Medicine, vol. 26, no. 2, pp. 278-284, 1998.

[77] U. G. Longo, A. Lamberti, N. Maffulli, and V. Denaro, “Tendon augmentation grafts: a systematic review," British Medical Bulletin, vol. 94, pp. 165-188, 2010.

[78] U. G. Longo, A. Lamberti, N. Maffulli, and V. Denaro, "Tissue engineered biological augmentation for tendon healing: a systematic review," British Medical Bulletin, vol. 98, pp. 31-59, 2011. 

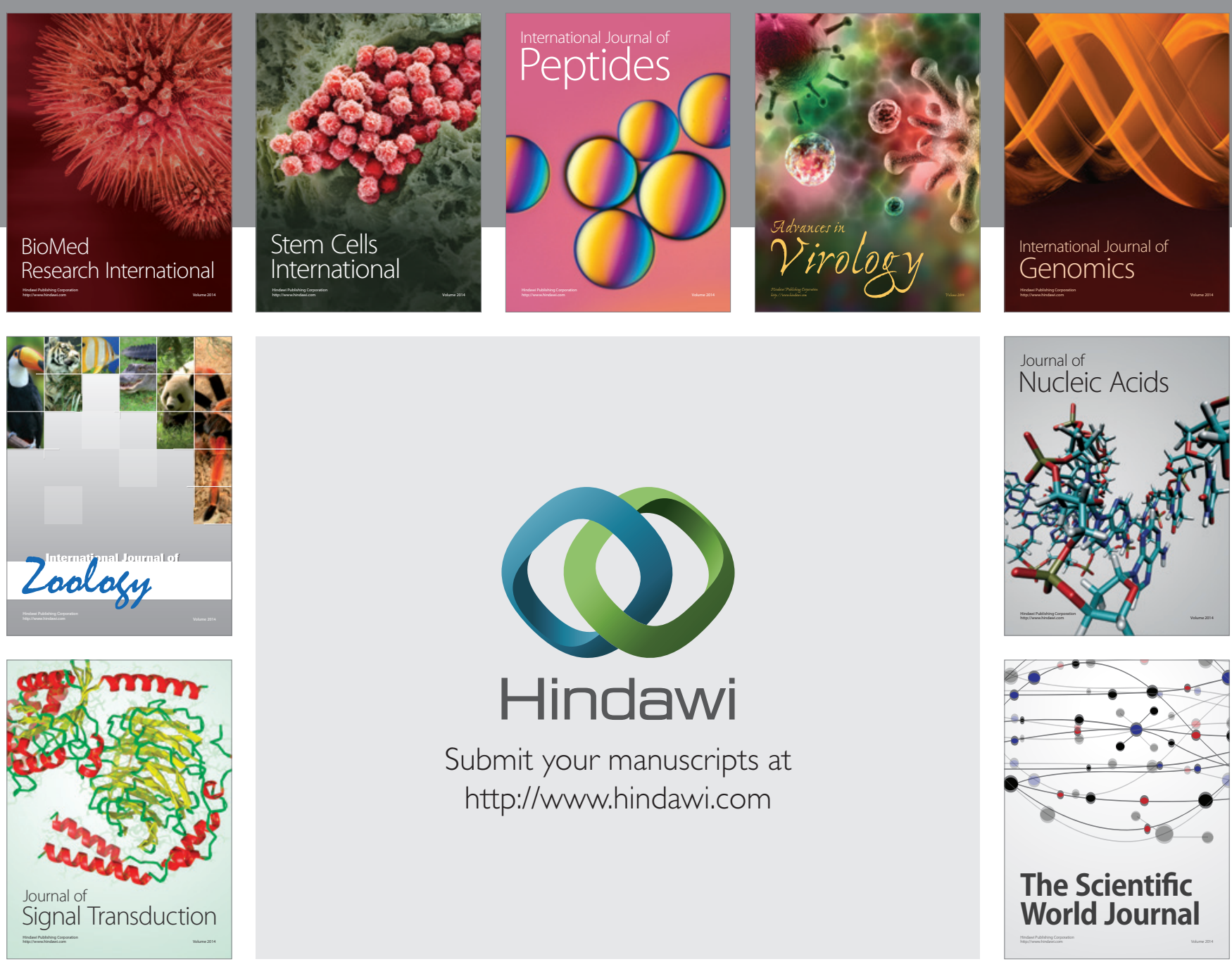

Submit your manuscripts at

http://www.hindawi.com
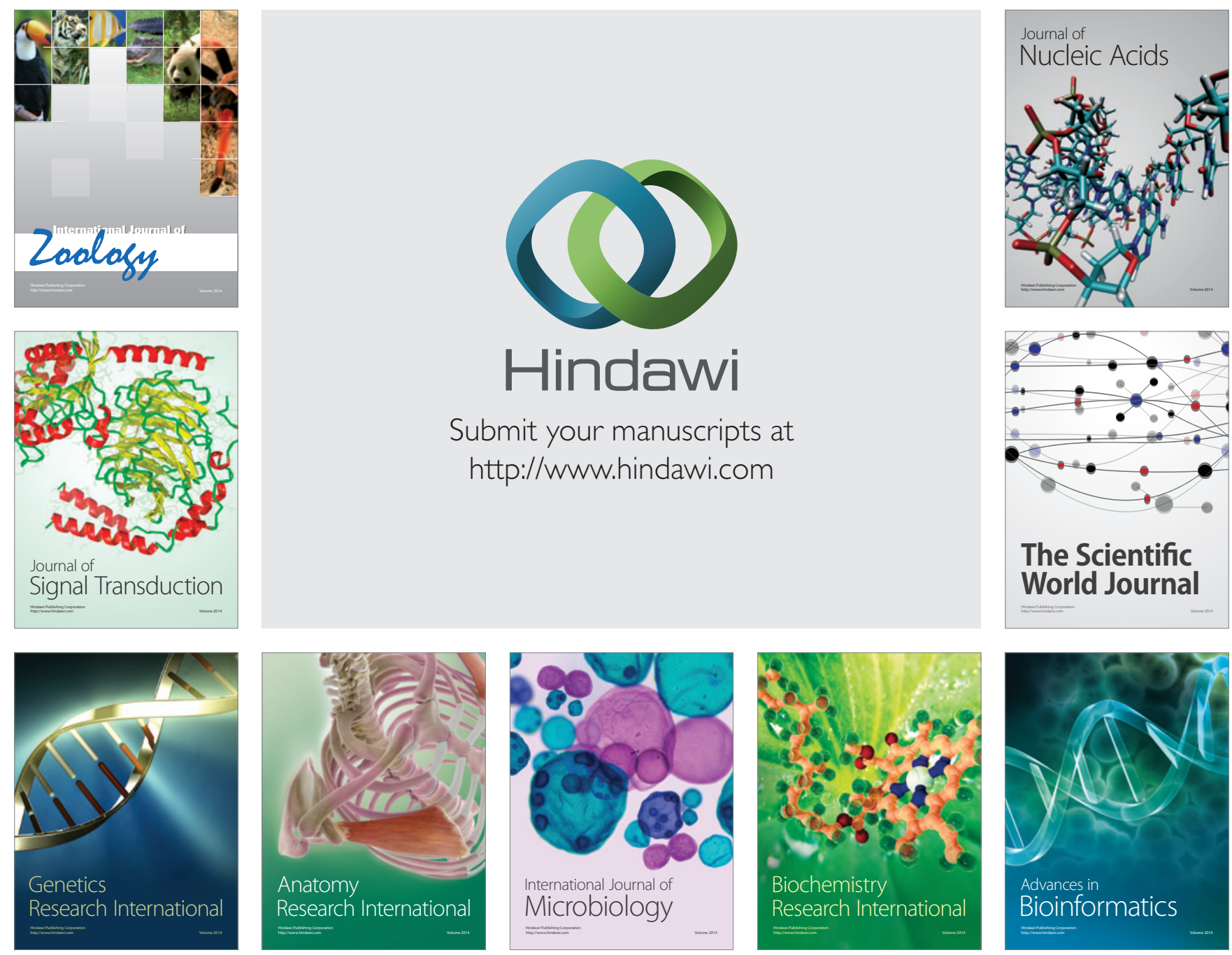

The Scientific World Journal
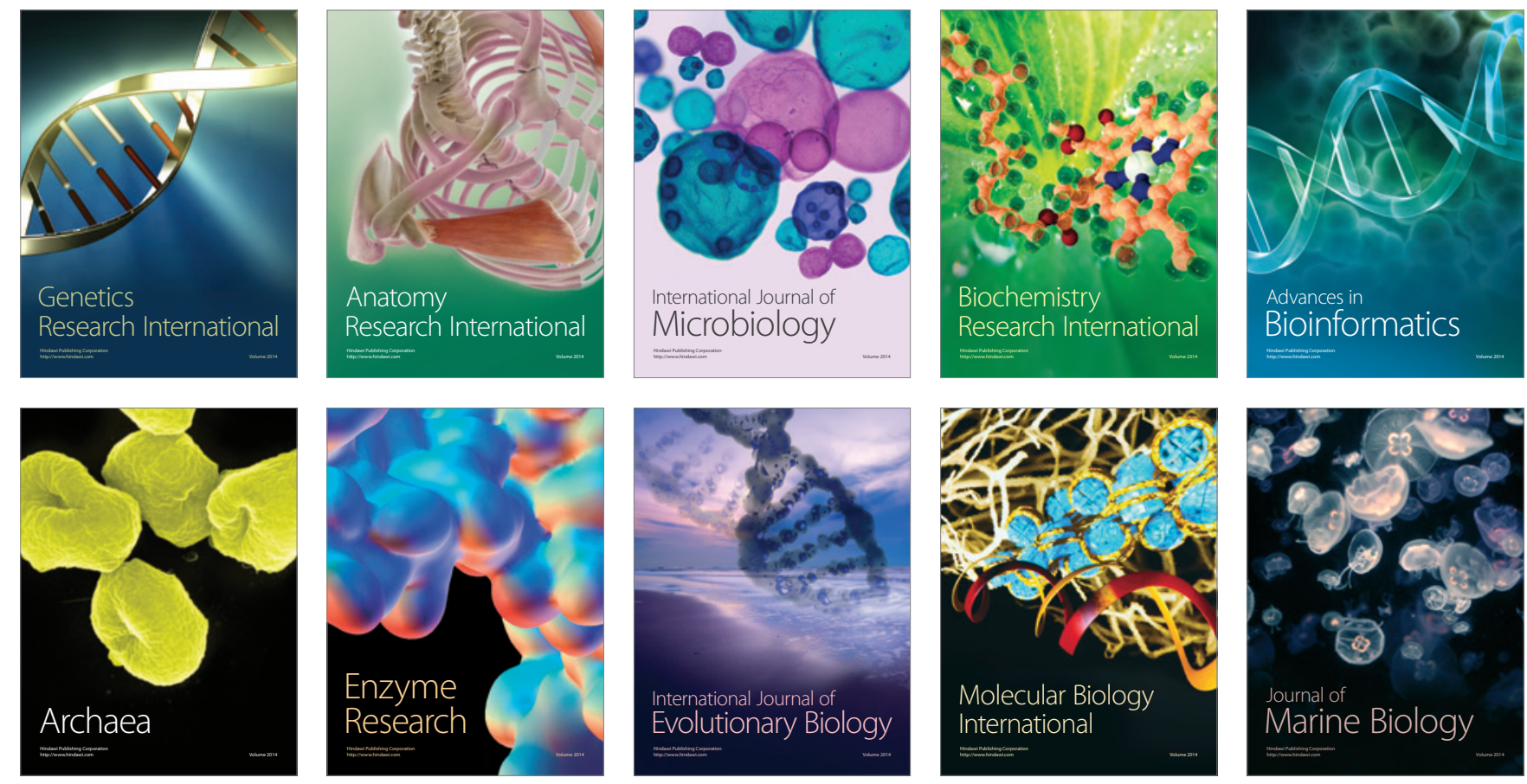